\title{
The Mental Health Act Commission and Second Opinions
}

\author{
LORD Colville, Chairman, Mental Health Act Commission
}

I am grateful for the opportunity of commenting on a recent article by Dr Paul Bridges, 'Psychosurgery and the Mental Health Act Commission' (Bulletin, August 1984, 8, 146-48). It may be useful to clarify the areas where we agree with him and to put into context matters in which he is critical. In the latter case I wish to consider whether his criticism is accurately directed at the Commission's policies.

The visit which the Commission's Secretary and I made to the Geoffrey Knight Unit was one of my first engagements. Our duties under Section 57 of the Mental Health Act 1983 began on 30 September of that year. We were well aware that recently a very large proportion of the psychosurgical operations in England and Wales had been performed at that unit. Moreover, there was the complication that, on that date, the Commission's functions suddenly had to be interposed in cases then current. They had to be fitted into the elaborate process which always precedes any such operation. Thus an opportunity to spend the best part of a day with Dr Bridges, Mr Bartlett and the rest of the Unit's team was most rewarding; so was the discussion with some former patients for whom the operation had been highly effective, and their families.

Dr Bridges accordingly sets out some of the problems which confronted us all. Patients whom the Commissioners first had to assess, under the new statutory duty, were far advanced on the path. They and their families had already agreed to the clinical advice that the operation was the right choice. Yet the patient's consent had again to be certificated. The doctor Commissioner (for it is always one of these) had to decide in each instance whether he agreed that in all the circumstances the operation was a proper medical procedure. Small wonder, then, that initially this extra stage caused some distress to patients who by definition were very ill, and disruption to the staff of a closely knit and well-organized Unit. There was, indeed, also the difficulty in relation to the patient's consent; the three Commissioners had to be assembled at a time when their judgement could validly be exercised. If the patient was severely depressed, with short periods of remission, this was not always easily organized.

However, it had to be done. It was just these difficulties which led the Central Policy Committee to invite Dr Bridges to talk about the procedures. He says this was recent, but in fact it took place in December 1983. There was also present a complete team from the north of England who were anxious to advance the possibility of beginning a modest programme of psychosurgery for suitable patients in their Unit. Arrangements were agreed for each Unit to suit its own rather different requirements. In each case it was emphasized that these procedures were flexible and could be altered in the light of experience. The same would apply to any other hospital; the Commission has been engaged in discussion with other professional people who believe that, through psychosurgery, they too can contribute to that humane, caring and effective treatment of patients suffering from certain mental illness. This is because the Commission understands its duty to safeguard patients' rights as having two aspects: the avoidance of treatment, including, but by no means confined to, psychosurgery, which is unlikely to help their condition, and the availability of sound treatment to which, on a proper professional judgement, they should be entitled. The object is not merely to eliminate any abuses, but positively to enhance the prospects for a patient to live the most fulfilling life that is achievable.

Dr Bridges refers to a legalistic attitude. Yet one of the concepts which gave rise to the Commission was that of the multidisciplinary approach to mental health. This is reflected in the Secretary of State's appointment of the individual Commissioners, as well as some of the Act's provisions. It is true that only Section 57 requires three Commissioners, two not being doctors, to safeguard the patient's consent; but as a matter of inevitable, and highly desirable, practice multidisciplinary activity infuses everything which the Commission does. It seems to me, therefore, a mistake to deal with psychosurgery in isolation. After a year's experience in formulating policy, preparing a draft Code of Practice and monitoring the medical opinions given under Sections 57 and $58 \mathrm{I}$ am sure that the multidisciplinary approach operates satisfactorily in all the Commission's duties and responsibilities. Parliament expressly arranged for it to apply to psychosurgery; it seems strange that in that field alone it should be a failure. At any rate a study of Hansard will show that the issue was thoroughly debated, and the present law is the informed will of the legislature.

The 1983 Act imposes the need for a second opinion in a variety of clinical situations. By far the most frequent are those where a detained patient cannot or will not consent to ECT or a course of treatment by medication. Responsible medical officers and the Commission's appointed doctors have been finding a wide degree of accord. The appointed doctors mostly are or have been RMOs , $\mathrm{m}$ selves. Usually the proposals for a patient's treatment have been supported, rather than frustrated, by the statutory second opinion. That opinion is not one whereby the appointed doctor supplants with his own clinical preference the treatment favoured by the RMO. Rather it is a matter of being satisfied that the proposal accords with good medical practice. Where any disagreement has occurred, discussion between the doctors has almost invariably led to a shared decision. Even if disagreement persists, reconsideration can be given if the patient's circumstances change. There has been a most positive response to the legislation in this field. Very many doctors have found a 
second opinion supportive in the difficult decisions they have to make. Even those initially reluctant have started to find that the new system looks after the interests of patient and doctor alike. Any system can be made to fail by those determined on failure. The Commission's perception is that the opposite is occurring and we welcome and seek to advance this constructive response.

The question, of course, arises under all provisions in the Act for a second opinion: who is and remains responsible for the patient? The answer is the doctor in charge of the patient's treatment, who, for detained patients, is the RMO. The second opinion is not imposed on him; it is not an insistence by the second opinion doctor on treatment which he would have chosen to give if the primary decision had been his own. Perhaps, in a difficult area of medicine, Parliament has seen fit to attempt a reinforcement of the RMO's clinical opinion, or room for professional discussion. Many doctors now view it thus. I find it impossible, therefore, to extract from that overall pattern, involving standard treatments for mental disorder, the comparatively rare case of psychosurgery. The idea of a medical second opinion there implies no different approach. What the Act adds is another stage, since the operation is irreversible. The two non-medical Commissioners join their doctor colleague in confirming the vital question of the patient's consent. Dr Bridges' article asserts that in some cases there certainly can be doubt on this point. We agree; and would add that the task is not made any easier if access to the patient's notes is denied.

It comes to this. The 1983 Act requires second opinions for a variety of treatments. In every case there is, in theory, a power of veto. In every case there is, in practice, a chance for the hospital staff concerned to seek confirmation of their own judgement from an independent source. The second is the positive approach. Dr Bridges, however, seems to look upon the scheme of the Act as one which threatens the professional opinion and advice of a whole range of experts. Then, in his addendum (Bulletin, September 1984, 8, 172), he brings in the suicide. That is indeed an emotive matter. I hardly think it necessary to say that the Commission would earnestly seek to avoid any decision which leads a patient to suicide. Yet there is a risk in many cases of mental illness. Possibly some consultants have never suffered such an outcome in their patient; just possibly some have never known about it. The danger must not affect and has not affected in the past the application of bona fide professional judgement.

I am here in a difficulty. All professional people are aware of that absolute quality of confidentiality for any client's case. My legal background ensures that the rule shall be maintained. Thus I cannot discuss in public the decision reached in respect of any individual patient, nor the reasons for it, fully though I have investigated it. Nor am I prepared to comment on the professional skills of anyone called upon to give a second opinion under Sections 57 or $\mathbf{5 8}$. I must be content with saying that I find it hard to accept that with all the advice available to him the Secretary of State was so inept in his appointments; that he chose doctor Commissioners not one of whom is fit to carry out the task imposed by the Act, even in psychosurgery cases; that not one of them is qualified to discuss with the RMO the alternatives available in the unusual case of a disagreement.

The situation may be different in Scotland and North America. Within the last few years Parliament debated at length, for England and Wales, all the controversial questions raised in Dr Bridges' article. The fact must be faced that it was decided on behalf of society to impose a check on certain matters of medical discretion. It is his right to disagree with those decisions and in a recent letter I have told him that the Commission respects him no less on that account. He will doubtless pursue the matter in the correct forum at Westminster. The Commission, however, was created by the same legislation. It is set up, among other things, to make the new system work. I have tried to describe how it seeks to do so. I do not think that the Commission membership is inadequate, or that its procedures are faulty. As to procedures, there is always room for further thought, but I am puzzled by Dr Bridges' suggestion, at the end of the article, of a new system at his Unit. We agree with him that the current method, devised with his co-operation, is working quite well.

The innovations in the 1983 Act may not be popular in every quarter. There is, however, little latitude in the duties laid on the Commission as regards second opinions. Within the limits of our discretion it is intended to continue identifying and seeking to solve the practical problems as they emerge.

\section{Revised regulations for the MRCPI}

The Royal College of Physicians of Ireland, at its Annual Stated Meeting on 18 October 1984, agreed to include the MRCPsych under the qualifications agreed for exemption from MRCPI Part I, under its Bye-Law 18. This means that those who hold the MRCPsych may proceed directly to MRCPI Part II, which, as is probably known, may be taken in the special subject of psychiatry.
The format is clinical, written and oral examinations in psychiatry, and clinical and oral examinations in general medicine, with special reference to neurology and psychiatry.

It is hoped that this move may enable psychiatrists to continue to exert influence within one of the major academic bodies in medicine in Ireland. 